\title{
Analysis and Design of Foot Bridge Connecting (2nd Floors) of Block A and Block B of MIET, Jammu
}

\author{
Akhil Sharma, Ashwani Kumar, Sunil Sharma, Arun Singh Chib, \\ **Rakesh Abrol \\ *Student, Dept. of Civil Engineering, MIET Jammu, J\&K, India \\ **Assistant Professor, Dept. of Civil Engineering, MIET Jammu, J\&K, India
}

\begin{abstract}
Foot Bridge is a Bridge designed for pedestrian traffic which are used to let people cross the road safely without disturbing the traffic below. There was a need to join the two blocks of MIET College, Jammu so as to access the passage in rain and other climatic effects and also to increase the aesthetics of the campus. A foot bridge is designed two connect the two corridors of the two blocks. This project mainly consists of the detailed design of such a foot bridge by considering manual and software approach. Survey of the site is done both by QGIS software and manually by Theodolite, plotted using AutoCAD. The design and analysis of foot bridge is done using STAAD.pro connect edition.
\end{abstract}

Keywords- Foot Bridge, Pedestrian Bridge, STAAD.Pro, Finite element Analysis.

\section{INTRODUCTION}

A footbridge (also a pedestrian bridge, pedestrian overpass, or pedestrian overcrossing) is a bridge designed solely for pedestrians. While the primary meaning for a bridge is a structure which links "two points at a height above the ground", a footbridge can also be a lower structure, such as a boardwalk, that enables pedestrians to cross wet, fragile, or mashy land. Bridges range from stepping stones-possibly the earliest manmade structure to "bridge" water-to elaborate steel structures. Another early bridge would have been simply a fallen tree. In some cases a footbridge can be both functional and a beautiful work of art.

There was a need to join the two blocks of MIET College, Jammu so as to access the passage in rain and other climatic effects and also to increase the aesthetics of the campus. A foot bridge is designed two connect the two corridors of the two blocks. This project mainly consists of the detailed design of such a foot bridge by considering manual and software approach. This project mainly consists of the detailed design of such a foot bridge by considering manual and software approach. Survey of the site is done both by QGIS software and manually by Theodolite, plotted using AutoCAD. The design

3) A footbridge to an orthodox church in Greece

4) The Chain of Rocks Bridge near St. Louis, Missouri

5) The Cork town Footbridge in Ottawa

6) The Davenport Sky bridge in Davenport, Iowa

7) The Dunlop Bridge at the Circuit de la Sarthe, Le Mans, Sarthe, France

8) The Esplanade Riel in Winnipeg, Manitoba

9) The Gates head Millennium Bridge, London, England

10) The Goodwill Bridge at Brisbane, Australia

11) The Ha'penny Bridge in Dublin, Ireland and analysis of foot bridge is done using STAAD.pro connect edition.

From model generation, analysis and design to visualization and result verification, STAAD Pro is the professional's choice for steel, concrete, timber, aluminum and cold-formed steel design of low and high-rise buildings, culverts, petrochemical plants, tunnels, bridges, piles and much more. To perform an accurate analysis a structural engineer must determine such information Structural loads, geometry, support conditions, and materials properties. The results of such an analysis typically include support reactions, stresses and displacements. This information is then compared to criteria that indicate the conditions of failure. Advanced structural analysis may examine dynamic response, stability and non-linear behavior.

\section{Technology domain:}

The proposed solution i.e. Foot bridge is as per modern trends in civil engineering.

It falls under the domain of design of structures.

The approach used is analytical by considering manual and software approach.

\subsection{Types}

Different types of design footbridges include:

- Timber footbridges

- Steel footbridges

- Concrete footbridge

Footbridges can also be built in the same ways as road or rail bridges; particularly suspension bridges and beam bridges. Some former road bridges have had their traffic diverted to alternative crossings and have become pedestrian bridges; examples in the UK include The Iron Bridge at Ironbridge, Shropshire, the Old Bridge at Pontypridd and Windsor Bridge at Windsor, Berkshire. Most footbridges are equipped with guard rails to reduce the risk of pedestrians falling.

Various foot bridges:

1) Tilak Nagar Station in Mumbai.

2) A pedestrian over cross in Nanjing Road, Shanghai

12) The Hungerford Bridge and Golden Jubilee Bridges, London, England

13) The Jade Belt Bridge in the Summer Palace in Beijing

\section{METHODOLOGY-}

2.1. Survey: It was done using Theodolite and was then plotted using AutoCAD.( From The Drafted Plan: The Calculated span $=30 \mathrm{~m}$ ) 


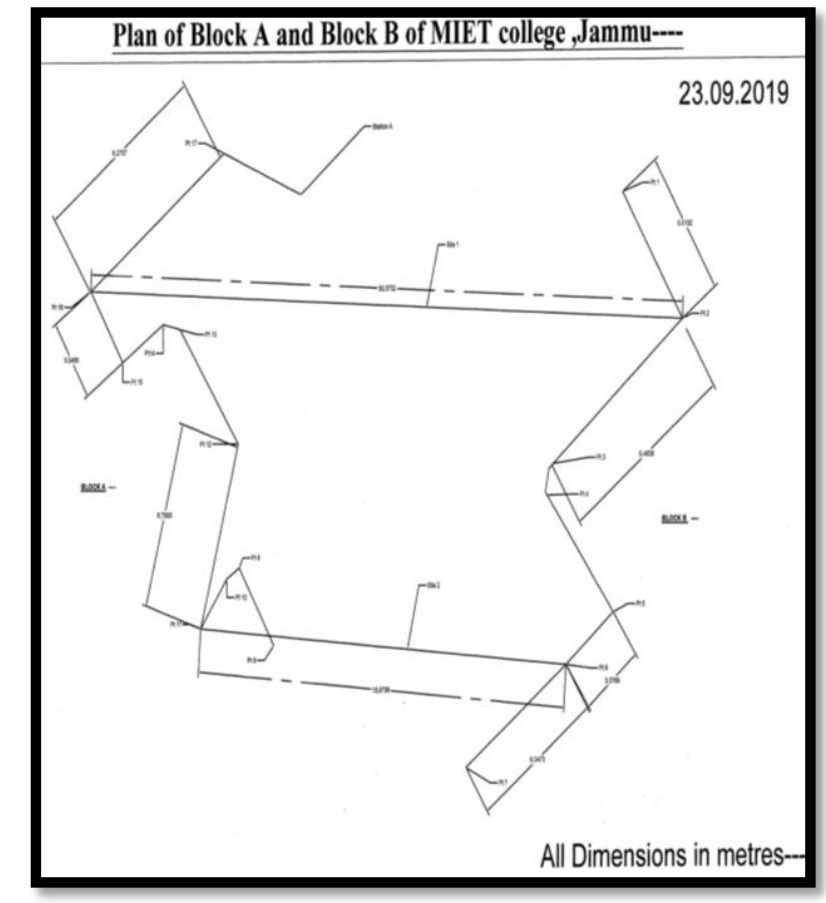

\begin{tabular}{|l|l|l|l|}
\hline Points & Staff Readings & Angles & Distance(m) \\
\hline BM 1 & 1.71 & $0^{\prime}$ & 16.68 \\
\hline 2 & 1.73 & $13^{\prime}$ & 20.3 \\
\hline 3 & 1.63 & $37^{\prime} 40^{\prime \prime}$ & 16.22 \\
\hline 4 & 1.605 & $40^{\prime} 20^{\prime \prime}$ & 16.6 \\
\hline 5 & 1.3 & $43^{\prime}$ & 22.1 \\
\hline 6 & 1.28 & $51^{\prime}$ & 21.8 \\
\hline 7 & 1.17 & $67^{\prime} 30^{\prime \prime}$ & 22.3 \\
\hline 8 & 1.37 & $95^{\prime}$ & 16.23 \\
\hline 9 & 1.42 & $103^{\prime} 30^{\prime \prime}$ & 13.75 \\
\hline 10 & 1.39 & $105^{\prime} 40^{\prime \prime}$ & 14.3 \\
\hline 11 & 1.54 & $108^{\prime} 30^{\prime \prime}$ & 16.4 \\
\hline 12 & 1.625 & $110^{\prime}$ & 9.5 \\
\hline 13 & 1.87 & $142^{\prime} 30^{\prime \prime}$ & 7.9 \\
\hline 14 & 1.87 & $147^{\prime}$ & 8.5 \\
\hline 15 & 1.87 & $147^{\prime}$ & 11 \\
\hline 16 & 1.835 & $162^{\prime} 30^{\prime \prime}$ & 11.4 \\
\hline 17 & 1.85 & $200^{\prime} 40^{\prime \prime}$ & 4.25 \\
\hline
\end{tabular}

\subsection{Specifications of Foot Bridge:}

1) $\mathrm{Span}=30$ meter.

2) Clear walking width between main girders $=2$ meter.

3) Clear Height of Bridge $=1.8 \mathrm{~m}$

4) Type of truss Configuration $=$ Pratt Truss.

5) Plate thickness $=0.02$ meter at bottom and 0.01 meter at top.

6) All members are of mild steel (angles and plates)

7) Site location $=J \& K($ Earthquake zone $V$ )

“As per IS 800:2007 clause no. 2.2.4.1

Unit mass of steel, $p=7850 \mathrm{~kg} / \mathrm{m}^{3}$.

Modulus of elasticity, $E=2.0 \times 10^{5} \mathrm{~N} / \mathrm{mm}^{2}$."

\subsection{Load Calculations:}

1. Dead loading as per IS 875 Part 1 .

2. Live loading $=\frac{(\text { no.of persons }(150) \times 75 \mathrm{~kg} \times 9.81)}{(30 \times 1)}=3.67$

$$
\mathrm{KN} / \mathrm{m}^{2} \sim 4.0 \mathrm{KN} / \mathrm{m}^{2} \text {. }
$$

\section{Earthquake loading as per IS 1893:2016}

Then the model was designed in AutoCAD and was then imported to staad.pro connect edition where after applying the materials, dimensions, Loading conditions etc Analysis was run and various calculations obtained from staad.pro was interpreted and any beam failure was redesigned until we got a stable structure. The following is the final details and specifications.

\subsection{View of the STAAD.Pro user interface:}

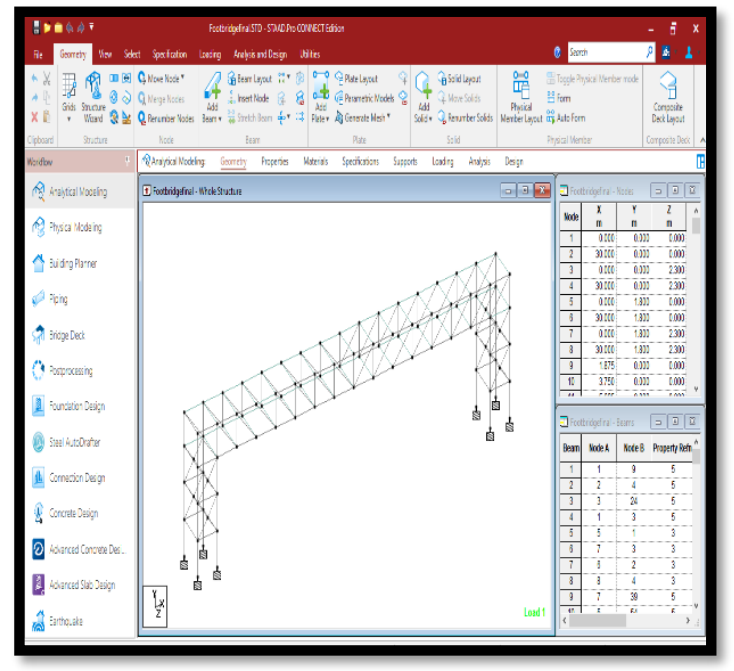

\subsection{D View of the Foot Bridge (STAAD.Pro Modal):}

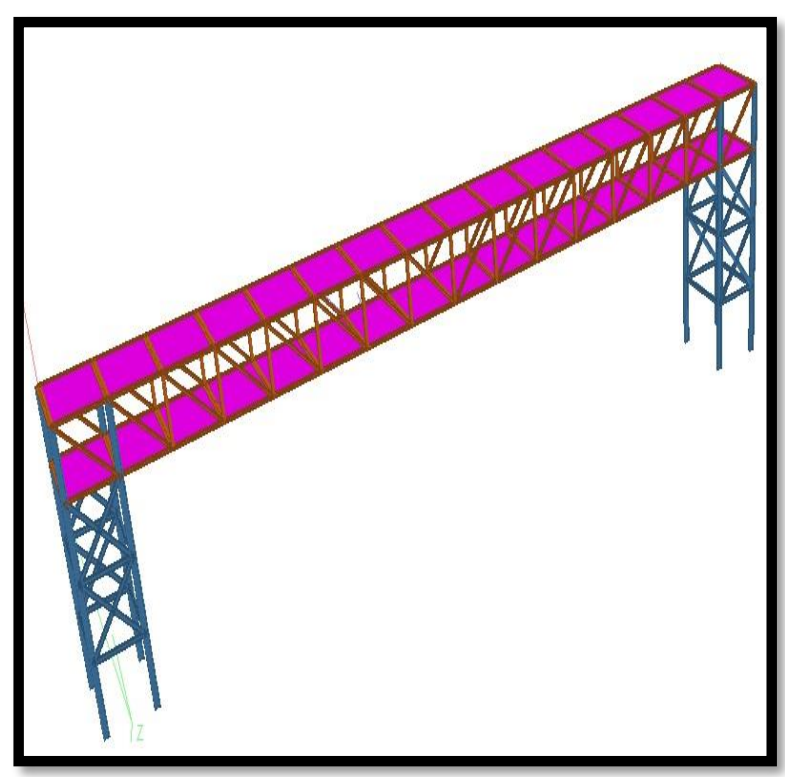




\subsection{Earthquake Loading-}

Shown in $\mathrm{X}$ and $-\mathrm{X}$ direction (similarly are in other directions).
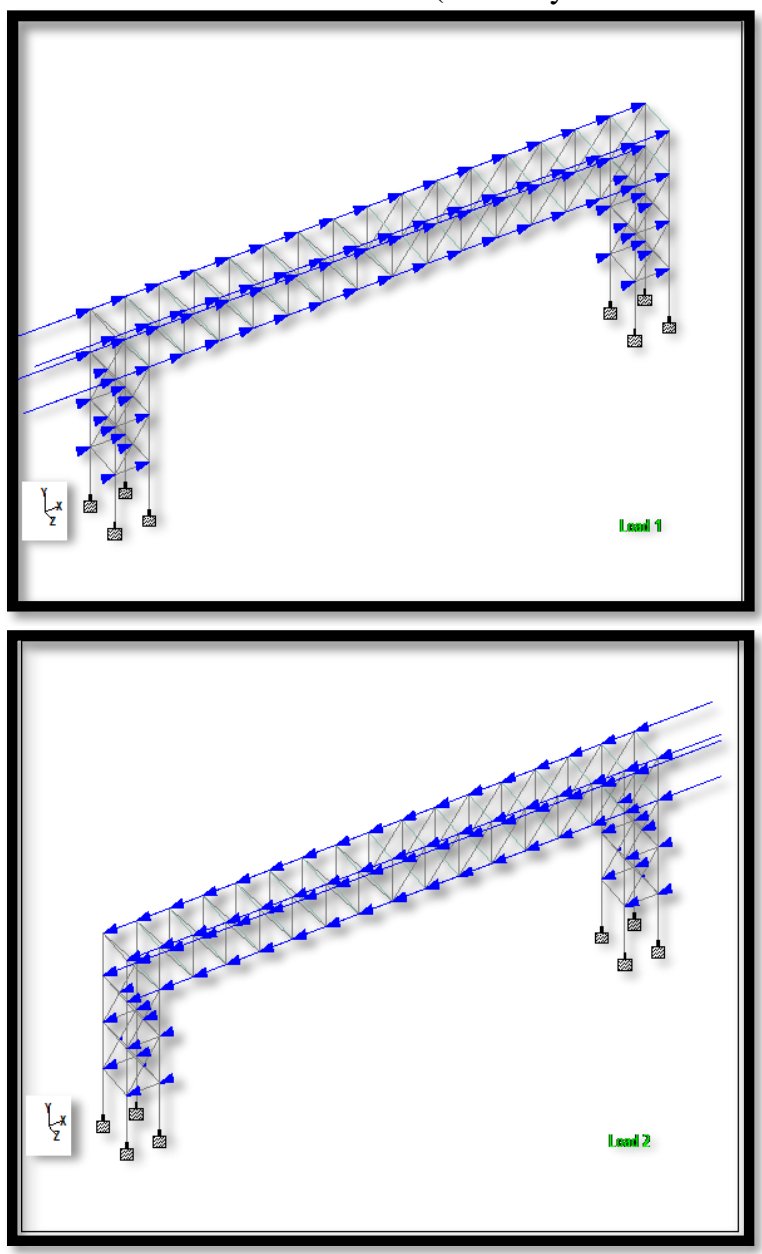

2.7. Section Properties after designing:-

\begin{tabular}{|c|c|c|c|c|}
\hline Section & $\begin{array}{l}\text { Area } \\
\left(\mathrm{cm}^{2}\right)\end{array}$ & $\begin{array}{c}\mathrm{I}_{\mathrm{W}} \\
\left(\mathrm{cm}^{4}\right)\end{array}$ & $\begin{array}{c}I_{z} \\
\left(\mathrm{~cm}^{4}\right)\end{array}$ & Material \\
\hline ISABOX80x10 & 30.200 & 347.120 & 177.967 & STEEL \\
\hline ISMB200 & 30.800 & 137.000 & $2.11 E+3$ & STEEL \\
\hline ISA90X90x10 & 34.200 & 492.704 & 258.363 & STEEL \\
\hline ISLB125 & 15.100 & 43.400 & 407.000 & STEEL \\
\hline ISA9OX900X10 & 34.200 & 492.704 & 258.363 & STEEL \\
\hline ISABOX80X10 & 30.200 & 347.120 & 177.967 & STEEL \\
\hline
\end{tabular}

2.8. Total dead load after designing:-

\begin{tabular}{|l|l|l|}
\hline Profile & $\begin{array}{l}\text { Length } \\
\text { (meter) }\end{array}$ & Weight(KN) \\
\hline LD ISA90x90 $\times 10$ & 211.15 & 55.474 \\
\hline LD ISMB200 & 62.40 & 14.764 \\
\hline LD ISA80 $x 80 \times 10$ & 129.97 & 30.153 \\
\hline ST ISLB125 & 77.26 & 8.962 \\
\hline & & Total $=109.353$ \\
\hline
\end{tabular}

\subsection{Steel Design Results From STAAD.pro:}

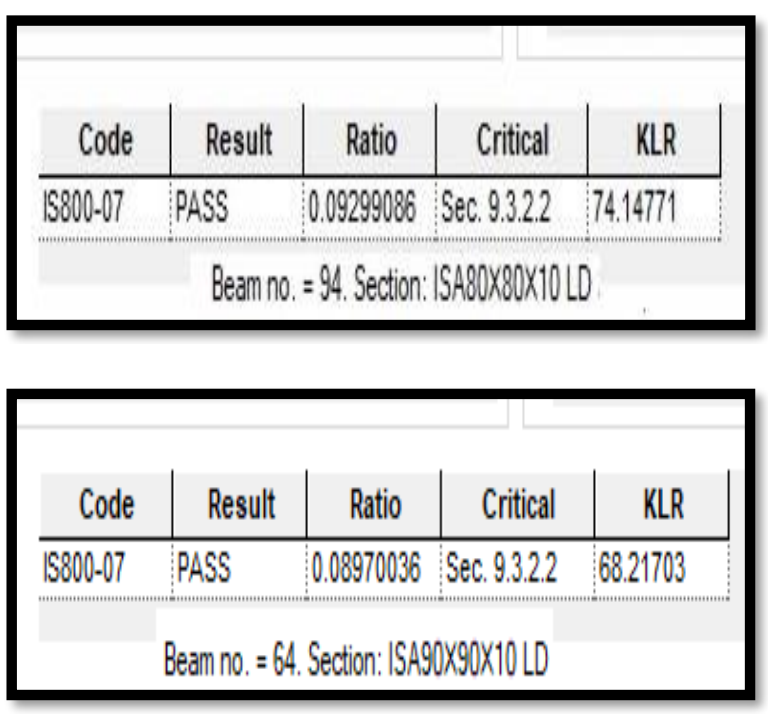

\begin{tabular}{|c|c|c|r|r|}
\hline Code & Result & Ratio & Critical & KLR \\
\hline IS800-07 & PASS & 0.1693656 & Sec. 9.3 .1 .1 & 80.8531 \\
\hline \multicolumn{6}{c|}{ Beam no. $=$ 346. Section: ISLB125 } \\
\hline
\end{tabular}

\begin{tabular}{|c|r|r|r|r|}
\hline Code & Result & Ratio & Critical & KLR \\
\hline IS800-07 & PASS & 0.4723538 & Sec. 9.3 .2 .2 & 94.82984 \\
\hline \multicolumn{6}{c|}{} \\
Beam no. $=$ 297. Section: ISMB200 \\
\hline
\end{tabular}

\section{CONCLUSIONS:}

1) The whole study was done on STAAD.Pro and the structure comes out to be stable as per guidelines.

2) Staad.pro provides an extremely flexible modeling environment, broad spectra of design codes, and covers all aspects of structural engineering.

3) Designing in Staad.pro is lot quicker and more accurate, all the diagrams like shear force diagram, bending moment diagram etc can be easily obtained and real time visualization of the behavior of structure can also be animated.

4) All the loading conditions like seismic loads, wind loads, dead and live loads can easily be taken into account as per Indian standards.

5) Moreover this computer simulation technique provides us a stability check criteria for members and sections.

6) We can have a clear vision of the estimation of materials to be used. 
7) This simulation study provides us an ease of determining stress contours, by which we can easily predict premature failure and yielding limit of sections.

\section{CONFLICT OF INTEREST:}

On behalf of all authors, the corresponding author states that there is no conflict of interest.

\section{REFERENCES:}

[1] IS 800:2007 Code of Practice for General Construction in Steel, Bureau of Indian Standards, 2007

[2] IS : 875 (Part I) Dead Loads - Unit Weights Of Building Materials And Stored Materials

[3] IS: 875 (Part 2) Code Of Practice For Live Loads

[4] Is-1893(part 1)-2016 Code of practice for earthquake resistant design of structures

[5] Steel Tables- M.K.S and S.I units, R. Agor, Birla Publications Pvt. Ltd, 2010.

[6] Design of Steel Structuresec, N. Subramanian.

[7] Design of Steel Structuresee, B.C. Punmia, Ashok Kumar Jain \& Arun Kumar Jain, Lakshmi Publications, New Delhi.

[8] Design of Steel Structures ${ }^{e c}$, S.K. Duggal, Tata McGraw-Hill Publishing Company Limited, New Delhi. 